\title{
KAJIAN ETNOSEMANTIK DALAM TOPONIMI WILAYAH KABUPATEN DAN KOTA CIREBON
}

Conference Paper · May 2017

CITATIONS

0

5 authors, including:

\section{Bayu Iqbal Anshari}

Universitas Pendidikan Indonesia

3 PUBLICATIONS 0 CITATIONS

SEE PROFILE
READS

387

\section{Moh. Dede}

Universitas Pendidikan Indonesia

4 PUBLICATIONS 0 CITATIONS

SEE PROFILE

Some of the authors of this publication are also working on these related projects: 


\title{
KAJIAN ETNOSEMANTIK DALAM TOPONIMI WILAYAH KABUPATEN DAN KOTA CIREBON
}

\author{
Bayu Iqbal Anshari ${ }^{1}$, Moh. Dede ${ }^{2}$, Rio Tirtayasa ${ }^{1}$, Tiryadi $^{1}$, Kemal Musthafa $^{1}$ \\ ${ }^{1}$ Departemen Pendidikan Bahasa dan Sastra Indonesia \\ Universitas Pendidikan Indonesia \\ ${ }^{2}$ Departemen Pendidikan Geografi \\ Universitas Pendidikan Indonesia \\ bayuiqbal36@student.upi.edu, m.dede.geo@gmail.com
}

\begin{abstract}
ABSTRAK
Cirebon merupakan salah satu wilayah pesisir yang memiliki banyak keunikan budaya mereka. Budaya Cirebon merupakan budaya hasil akulturasi antara budaya Jawa dan Sunda akibat proses sejarah. Hal ini yang menjadikan Cirebon merupakan wilayah pusat persilangan kebudayaan yang ada di Jawa Barat bagian utara. Sehingga, pengaruh dua kebudayaan tersebut berimplikasi pada perbedaan bahasa dengan daerah lainnya di Jawa Barat, mengakibatkan penaman-penamaan tempat yang ada memiliki karakteristik tersendiri baik yang tersebar di wilayah Kabupaten maupun kota Cirebon. Objek penelitian yang digunakan adalah nama-nama tempat yang ada di wilayah Cirebon dengan pisau analisis yang kami gunakan adalah etnosemantik untuk mengungkap asal usul dan latar belakang penamaan tempat di Cirebon, dengan metode penelitian yang digunakan adalah metode deskriptif kualitatif. Rumusan masalah yang akan kami kaji adalah bagaimana asal usul nama-nama tempat di Cirebon dan pengetahuan masyarakat Cirebon terhadap toponimi wilayah Cirebon. Toponimi di wilayah Cirebon sangat dipengaruhi aspek fisik, sosial budaya, aspek fisik tersebut meliputi keadaan geografis, flora dan fauna. Sedangkan, aspek sosial budaya meliputi sejarah, adat istiadat, nama tokoh, cita-cita, kesenian, bangunan dan aktivitas masyarakat. Upaya pelestarian toponim di Cirebon melalui serangkaian kajian dan pemertahanannya agar nama-nama tempat masyarakat Cirebon itu sendiri dan Indonesia pada umumnya.
\end{abstract}

Kata Kunci: budaya, Cirebon, toponim

\section{PENDAHULUAN}

Manusia dan lingkungannya merupakan dua entitas yang tidak dapat dipisahkan semenjak hadirnya manusia di permukaan bumi. Adanya kebutuhan hidup manusia yang beragam mengharuskan mereka untuk peroleh berbagai sumber daya di wilayah lain yang memiliki perbedaan satu dengan lainnya. Sebagai usaha untuk menandai dan membagikan informasi kepada sesamanya mengenai wilayah tersebut, maka pemberian berbagai nama disesuaikan dengan fenomena geografis yang menjadi ciri suatu wilayah. fenomena geografis berupa unsur rupa bumi yang berupa gunung, bukit, sungai, tanjung, lembah, pulau dan sebagainya diberi nama oleh manusia dengan tujuan untuk mempermudah identifikasi tempat tersebut sehingga mudah dikenali oleh orang lain (Rais, 2008). 
Dalam perkembangannya, pemberian nama suatu wilayah juga berkaitan dengan berbagai fenomena sosial, budaya, dan peristiwa yang dialami manusia, seperti nama babakan dan kampung (Miftah, 2008; Rais: 2008). Babakan atau kampung merupakan salah satu nama yang digunakan sebagai sarana aktualisasi suatu masyarakat di tempat baru agar mudah dikenali. Artinya, setiap peristiwa dan pengetahuan masyarakat adalah salah satu contoh yang bisa diambil sebagai penamaan suatu wilayah.

Berbagai fenomena alam, sosial, budaya, dan peristiwa yang dialami oleh manusia yang diabadikan dalam penamaaan wilayah, turut pula mendapatkan legalitas dalam Undang-Undang No. 32 Tahun 2004 tentang Pemerintahan Daerah bahwa penamaan suatu wilayah berkaitan dengan unsur rupa bumi sebagai bagian dari khazanah kebudayaan bangsa. Hal ini membuktikan bahwa setiap nama mengandung berbagai makna yang bermanfaat guna memanfaatkan dan menggali berbagai potensi wilayah yang dikenal sebagai toponimi.

Toponimi bisa diartikan sebagai cabang onomastika yang menyelidiki penamaan unsur-unsur geografis pada nama-nama tempat. Akan tetapi, sebagian besar orang belum menyadari pentingnya sebuah nama dengan berbagai aturan yang mengikatnya. Hal ini akan mudah terlihat pada nama-nama pusat pertumbuhan yang biasanya lebih dikenal daripada nama kecamatan daerah tersebut. Contoh kongkrit dari permasalahan tersebut adalah Jababeka City. Jika kita merujuk pada Peraturan Pemerintah Republik Indonesia Nomor 13 Tahun 2004 Tentang Penamaan, Pendaftaran dan Penggunaan Varietas Asal Untuk Pembuatan Varietas Turunan Esensial, nama tersebut setidaknya melanggar dua aturan, yaitu penamaan tidak berbasis kearifan lokal dan menggunakan bahasa asing. Tentunya ini adalah salah satu bentuk invasi budaya asing untuk meredam local knowledge masyarakat setempat. Oleh karena itu, banyak sekali definisi toponimi yang disampaikan oleh berbagai ahli dan lembaga sebagai turunan dari aturan yang telah disebutkan tadi. Setelah itu, penataan nama-nama tempat yang didasarkan pada cerita rakyat (folklor) yang membicarakan tentang asal-usul nama sebuah pulau, gunung, sungai, bukit, kota, dan desa berdasarkan pada sejarah, makna, penggunaan dan tipologi (Bachtiar dkk., 2008; Perdana, 2013; BRKP, 2003).

Selain itu, mengutip pendapat Saussure (1959) tentang konsep penanda dan petanda, maka toponimi dapat berfungsi sebagai sebuah penanda yang khas dari suatu tempat. Hal ini nampaknya bisa terlihat dari beragamnya fenomena alam yang berpadu dengan pluraritas sosial-budaya di Indonesia, memicu keberagaman penamaan suatu wilayah yang didasari atas kebudayaan setempat sebagai identitas. Sebagai contoh, dalam etnis sunda jika tempat tersebut terdapat sumber air biasanya akan memiliki awalan ci- atau leuwi. Artinya, cukup banyak 
toponimi yang berkaitan dengan aspek fisik, sosial dan budaya (Mutakin, 1999) Penamaan-penamaan tersebut tentunya menandakan bahwa toponim bukan hanya sebuah label, melainkan terdapat khasanah nilai yang masih terpendam.

Toponim sejumlah wilayah di Cirebon yang meliputi wilayah administrasi Kabupaten Cirebon dan Kota Cirebon merupakan terbentuk sebagai hasil akulturasi budaya Jawa dan Sunda (Anshari dan Dede, 2016). Salah satu wilayah kecamatan di Kota Cirebon, yakni Lemahwungkuk merupakan salah satu contohnya, dimana terdapat kata "lemah" yang berarti tanah dalam bahasa Sunda dan kata "wungkuk" yang dalam bahasa Jawa berarti bongkok. Sebagai penelitian kualitatif, pengumpulan data dilakukan hanya berdasarkan fakta dan fenomena yang memang secara empiris masih hidup pada penutur-penuturnya sehingga yang dihasilkan atau yang dicatat berupa perian bahasa yang biasa dikatakan dipadankan seperti potret (Sudaryanto, 1993). Instrumen yang digunakan dalam penelitian ini adalah human instrument dimana peneliti sendiri merupakan instrumen kunci (Sugiyono, 2008). Data yang telah terkumpul selanjutnya akan dianalisis menggunakan metode analisis makna yaitu etnosemantik.

Dengan menggunakan kajian bahasa dan budaya, etnosemantik digunakan agar bahasan permasalahan tetap pada tataran makna dengan mengungkap hubungan antara bahasa, budaya, pikiran sekaligus pola pikir masyarakat (Humaini, 2007; Duranti, 1997; Kramsc, 2001). Sehingga, persepsi masyarakat Cirebon akan terkuak melalui toponimi yang ada di daerah tersebut, dengan cara (1) mengetahui asal-usul yang melatarbelakangi penamaan tempat di Cirebon; (2) mengetahui klasifikasi dari toponimi Cirebon. Dengan demikian, kompleksivitas bentang alam dan sosial-budaya turut mempengaruhi pemberian nama di Cirebon sebagai konsekuensi keragaman alam dan sosial-budaya dapat memperkaya kajian toponimi di Indonesia. Hal ini perlu dilakukan guna melestarikan toponim Cirebon di tengah arus globalisasi dan modernisasi yang tidak terhindarkan.

\section{HASIL DAN PEMBAHASAN}

Cirebon merupakan wilayah yang terletak di ujung timur Jawa Barat dan berbatasan langsung dengan Jawa Tengah. Cirebon telah mengalami beberapa kali perubahan nama, diawali dengan nama "Caruban" yang berasal dari kata "carub". Carub sendiri bermakna campur. Kemudian, toponim tersebut berevolusi menjadi "Carbon" yang berarti "Pusat Jagat", karena tempat ini dulunya dianggap berada di tengah-tengah Pulau Jawa. Dari Carbon nama ini mengalami perubahan kembali menjadi "Cerbon" hingga akhirnya menjadi "Cirebon" yang kita kenal saat ini (Sudaryat, 2009; Sudjana, 2001). 
Tabel 1. Toponim Cirebon beserta Aspek Toponimnya

\begin{tabular}{|c|c|c|c|c|c|c|c|}
\hline No. & Nama & $\begin{array}{c}\text { Klasifikasi } \\
\text { Lingual }\end{array}$ & $\begin{array}{c}\text { Aspek } \\
\text { Toponim }\end{array}$ & No. & Nama & $\begin{array}{c}\text { Klasifikasi } \\
\text { Lingual }\end{array}$ & $\begin{array}{c}\text { Aspek } \\
\text { Toponim }\end{array}$ \\
\hline 1 & Arjawinangun & Kata & Sos-bud & 24 & Pabedilan & Kata & Sos-bud \\
\hline 2 & Astanajapura & Kata & Sos-bud & 25 & Pabuaran & Kata & Sos-bud \\
\hline 3 & Babakan & Kata & Sos-bud & 26 & Palimanan & Kata & Sos-bud \\
\hline 4 & Beber & Kata & Sos-bud & 27 & Pangenan & Kata & Sos-bud \\
\hline 5 & Ciledug & Kata & Fisik & 28 & Panguragan & Kata & Sos-bud \\
\hline 6 & Ciwaringin & Kata & Fisik & 29 & Pasaleman & Kata & Sos-bud \\
\hline 7 & Depok & Kata & Sos-bud & 30 & Plered & Kata & Sos-bud \\
\hline 8 & Dukupuntang & Kata & Fisik & 31 & Plumbon & Kata & Fisik \\
\hline 9 & Gebang & Kata & Fisik & 32 & Sedong & Kata & Sos-bud \\
\hline 10 & Gegesik & Kata & Fisik & 33 & Suranenggala & Kata & Sos-bud \\
\hline 11 & Gempol & Kata & Fisik & 34 & Susukan & Kata & Sos-bud \\
\hline 12 & Greged & Kata & Sos-bud & 35 & Susukanlebak & Kata & Sos-bud \\
\hline 13 & Gunungjati & Kata & Fisik & 36 & Talun & Kata & Sos-bud \\
\hline 14 & Jamblang & Kata & Fisik & 37 & Tengahtani & Kata & Sos-bud \\
\hline 15 & Kaliwedi & Kata & Fisik & 38 & Waled & Kata & Fisik \\
\hline 16 & Kapetakan & Kata & Sos-bud & 39 & Weru & Kata & Sos-bud \\
\hline 17 & Karangsembung & Kata & Fisik & 40 & Sumber & Kata & Sos-bud \\
\hline 18 & Karangwareng & Kata & Fisik & 41 & Harjamukti & Kata & Sos-bud \\
\hline 19 & Kedawung & Kata & Fisik & 42 & Kejaksan & Kata & Sos-bud \\
\hline 20 & Klangenan & Kata & Sos-bud & 43 & Kesambi & Kata & Fisik \\
\hline 21 & Lemahabang & Kata & Fisik & 44 & Lemahwungkuk & Kata & Fisik \\
\hline 22 & Losari & Kata & Fisik & 45 & Pekalipan & Kata & Sos-bud \\
\hline 23 & Mundu & Kata & Fisik & & & & \\
\hline
\end{tabular}

Secara administratif, Cirebon terbagi menjadi kota dan kabupaten dengan total 45 kecamatan dengan rincian 40 kecamatan di Kabupaten Cirebon dan lima kecamatan di Kota Cirebon. Toponim yang terdapat pada nama-nama kecamatan di Cirebon akan diklasifikasikan menjadi dua aspek yaitu fisik dan sosial budaya. (Mutakin, ) Aspek fisik menyangkut unsur hidrologis (air), unsur geomorfologis (bentuk lahan), dan unsur biologis (flora dan fauna) sedangkan aspek sosial budaya meliputi unsur sejarah, folklor, gagasan, maupun harapan.

Di Cirebon, terdapat 21 toponim kecamatan yang mengandung aspek fisik. Sedangkan, sebanyak 24 kecamatan lainnya diidentifikasi berasal dari aspek sosial budaya (lihat tabel 1). Persebaran toponim yang beraspek fisik lebih banyak di bagian barat daripada bagian timur Cirebon. Toponim yang berada di wilayah pesisir pantai cenderung didominasi oleh nama-nama tempat yang bermakna pada aspek sosial budaya. Meski begitu, toponim yang beraspek fisik bisa kita temui di sekeliling toponim yang bermakna sosial budaya. 


\section{Prosiding Seminar Internasional Leksikologi dan Leksikografi 2017 \\ "Teknologi Bahasa dan Budaya dalam Penelitian Leksikologi dan Leksikografi"}

Keberadaan toponim yang berkaitan erat dengan kondisi fisik umunya mengacu pada keadaan lingkungan alami Cirebon yang berada di wilayah dataran rendah beserta ekosistemnya. Toponim seperti Ciledug (air dengan material suspensi seperti tanah), Gebang (sejenis palm), Gegesik (tanjung), Kaliwedi (air dengan material suspensi seperti tana) dan Waled (tanah berlumpur) menunjukan karakteristik alamiah Cirebon sebagai wilayah pesisir yang berupa tanah dan bentuk lahannya dipengaruhi oleh aktivitas alluvial di masa lampau.

Adanya kecenderungan toponim yang berasosiasi dengan aspek sosial budaya seperti makna sejarah dan harapan masyarakat lebih banyak berkembang di wilayah Cirebon yang berbatasan langsung dengan laut karena masyarakat di wilayah pantai mudah terpengaruh budaya luar akibat banyaknya interaksi dengan masyarakat dari luar Cirebon, seperti makna Cirebon yakni caruban yang berarti campuran. Hal ini didukung dengan adanya faktor historis Cirebon sebagai pelabuhan dan area perdagangan antar wilayah.

Di sisi lain, terdapat pula perpaduan toponim yang berasal dari unsur sosial-budaya dengan fisik yang ada di Cirebon. Toponim Kapetakan (petak sawah), Susukan Lebak (irigasi/sodetan sungai), dan Tengahtani (lahan pertanian) menunjukan adanya aktivitas masyarakat dalam mengelola lingkungan fisik Cirebon yang berupa bentuk lahan proses alluvial menjadi lahan budidaya pertanian.

Keberagaman makna yang ditunjukan dari toponim semua kecamatan di Cirebon, menunjukan bahwa nama-nama tempat bukan hanya sekedar nama yang tiada arti seperti ungkapan William Shakespeare yakni what's in a name, yang mulai terjadi di Cirebon pada sejumlah kecamatannya yang telah memiliki eksonim seperti Talun (Cirebon Selatan), Kedawung (Cirebon Barat), dan Gunungjati (Cirebon Utara). Fenomena tersebut bila tidak ditanggulangi dengan baik dikhawatirkan akan menggeser makna asli dan sejarah wilayah tersebut.

\section{KESIMPULAN}

Toponimi adalah cabang onomastika yang menyelidiki penamaan unsur-unsur geografis yang dapat berupa nama-nama. Toponim sejumlah wilayah di Cirebon yang meliputi wilayah administrasi Kabupaten dan Kota Cirebon merupakan terbentuk sebagai hasil akulturasi budaya Jawa dan Sunda. Secara administratif, Cirebon terbagi menjadi kota dan kabupaten dengan total 45 kecamatan dengan rincian 40 kecamatan di Kabupaten Cirebon dan lima kecamatan di Kota Cirebon.Di Cirebon, terdapat 21 toponim kecamatan yang mengandung aspek fisik. Sedangkan, sebanyak 24 kecamatan lainnya diidentifikasi berasal dari aspek sosial budaya. Keberagaman makna yang ditunjukan dari toponim semua kecamatan di 
Cirebon, menunjukan bahwa nama-nama tempat bukan hanya sekedar nama, melainkan sebuah kekayaan yang harus dijaga oleh bangsa Indonesia.

\section{DAFTAR RUJUKAN}

Anshari, B. \& Dede, M. (2016). "Persepsi Istri Ideal dalam Lirik Lagu Tarling Istri Apa Polisi Karya Yoyo Suwaryo". dalam Sumiyadi, dkk. (ed). Prosiding Seminar Internasional Riksa Bahasa X: Literasi dan Budaya Bangsa. Bandung: Prodi Pendidikan Bahasa Indonesia, Sekolah Pascasarjana, Universitas Pendidikan Indonesia.

Duranti, A. (1997). Linguistic Anthropology. New York: Cambridge University Press.

Humaini, A. (2007). Leksikon untuk Unta ualam Bahasa Arab Kajian Etnosemantik. Skripsi Fakultas Bahasa dan Seni, Universitas Negeri Yogyakarta.

Kramsch, C. (2001). Language and Culture. New York: Oxford University Press.

Rais, J., dkk. (2008). Toponimi Indonesia. Jakarta: Pradnya Rosdakarya.

Miftah, Y. (2008). Fenomena Geografis di Balik Nama-nama Tempat (Toponim) di Wilayah Kota Bandung. Skripsi Fakultas Pendidikan Ilmu Pengetahuan Sosial, Universitas Pendidikan Indonesia

Mutakin, A. (1999). Suatu Strategi dan Implikasi Pembelajaran Nama Tempat pada Pembelajaran Geografi. Bandung: Jurusan Pendidikan Geografi FPIPS UPI.

Ruspandi, J. (2015). Makna Geografis Toponimi di Kota Cirebon. Skripsi Fakultas Pendidikan Ilmu Pengetahuan Sosial, Universitas Pendidikan Indonesia

Saussure, F. d. (1959). Course of General Linguistic. New York: The Philosophical Library. Inc.

Peraturan Pemerintah Republik Indonesia Nomor 13 Tahun 2004 Tentang Penamaan, Pendaftaran dan Penggunaan Varietas Asal Untuk Pembuatan Varietas Turunan Esensial.

Sudaryat, Y. (2009). Toponimi Jawa Barat (Berdasarkan Cerita Rakyat). Bandung: Disbudar Jawa Barat.

Sudjana, T. D. (2001). Kamus Bahas Cirebon. Bandung: Humaniora Utama Press.

Undang-Undang Republik Indonesia Nomor 32 Tahun 2004 tentang Pemerintahan Daerah 